\title{
PENGARUH MINAT MEMBACA CERITA PAHLAWAN PADA HASIL PENGAJARAN
}

\author{
INFLUENCE OF INTEREST READING STORIES HEROES ON LEARNING \\ W Gusmayanti1a, RSP Fauziah'2 ${ }^{2}$ dan I Muhdiyati ${ }^{1}$

\begin{abstract}
1Program Studi Pendidikan Guru Sekolah Dasar, Fakultas Keguruan dan Ilmu Pendidikan
Universitas Djuanda, Jl. Tol Ciawi No 1 Kotak Pos 35, Bogor Indonesia

${ }^{2}$ Program Studi Manajemen Pendidikan Islam, Fakultas Keguruan dan Ilmu Pendidikan

Universitas Djuanda, Jl. Tol Ciawi No 1 Kotak Pos 35, Bogor Indonesia

a Korespondensi: Wina Gusmayanti, Email: gusmayanti62@gmail.com

(Diterima: 31-03-2018; Ditelaah: 01-04-2018; Disetujui: 18-04-2018)
\end{abstract}

\begin{abstract}
The purpose of this study is to determine the influence of interest in reading the story of the hero of social sciince learning. The method used in this research is functional correlation method. The population in this study were students of SDN Pancawati 02 Class V A, which amounted to 30 students. The data used is done is a questionnaire of interest in reading the story of the hero. The conclusion from the end of this study shows the regression equation is the test results through regression analysis shows the similarity of regression $Y=22.6 \%$. + $0.608 \mathrm{X}$ can be said there is an influence interest in reading the story of the hero on the learning outcomes in the eyes of social science learning with a straightly related relationship. The coefficient of determination is $0.7922=0.627$. The value of the largest learning outcomes of students by $62.7 \%$ while 37.3 student learning outcomes is influenced by other factors
\end{abstract}

Keywords: interest in reading hero's story, social science learning.

\begin{abstract}
ABSTRAK
Tujuan penelitian ini adalah untuk mengetahui pengaruh minat membaca cerita pahlawan pada pembelajaran IPS. Metode yang digunakan dalam penelitian ini adalah metode kolerasi fungsional. Populasi yang dipakaikan dalam penelitian ini adalah siswa SDN Pancawati 02 Kelas V A, yang berjumlah 30 siswa. Data yang digunakan adalah dilakukan adalah angket minat membaca cerita pahlawan. Kesimpulan dari akhir penelitian ini menunjukan pada persamaan regresi yaitu hasil pengujian melalui analisis regresi menunjukkan adanya kesamaan regresi $\widetilde{Y}=22.6 \% .+0.608 \mathrm{X}$ dapat dikatakan terdapat pengaruh minat membaca cerita pahlawan pada hasil pembelajaran di mata pembelajaran IPS dengan hubungan yang terbanding lurus. Koefisien determinasi yaitu $0,792^{2}=0,627$. Nilai hasil belajar terbesar siswa sebesar $62,7 \%$ sedangkan 37,3 hasil pembelajaran murid dipengaruhi dengan faktor lain.
\end{abstract}

Kata kunci: hasil belajar IPS, minat membaca cerita pahlawan.

Gusmayanti, W., Fauziah, R. S. P., \& Muhdiyati, I. (2018). Pengaruh Minat Membaca Cerita Pahlawan pada Hasil Pengajaran. Didaktika Tauhidi: Jurnal Pendidikan Guru Sekolah Dasar, 5(2): 123-134. 


\section{PENDAHULUAN}

Salah satu tujuan pendidikan adalah yaitu membentuk kecerdasan siswa, namun banyak yang mempengaruhi kecerdasan siswa, misal dari Faktor genetik atau (IQ) Intelligence quotient, metode dan model pembelajaran yang dipakai dan digunakan guru juga berperan dalam mengembangkan kecerdasan siswa,minat membaca siswa, metode yang tepat akan menghasilkan hasil dan pembelajaran yang diharapkan, Salah satu hal yang bisa dicoba yang dapat meningkatkan hasil dan pembelajaran siswa adalah dengan banyak membaca dan menumbuhkan budaya baca.

Hasil studi telah dilaksanakan di "Most Litered National In This World" yang dikerjakan oleh "Central Connecticut State University" di tahun 2016 bulan maret menunjukkan peringkat Indonesia nomor enam puluh dari enam puluh satu negara dalam soal kemauan membaca. walaupun Data dari IKAPI (Ikatan Perilis Indonesia) 2015, menyatakan 93,4\% penduduk Indonesia bisa membaca kata-kata, namun hanya ada 30.000 buku yang dirilis tiap tahunnya, yang dirasa belum cukup untuk memajukan kebisaan tentang literasii.

Penelitian yang dilakukan oleh "Most Litered National In The World" yang dilakukan oleh "Central Connecticut State University" kita bisa mengambil sisi positif bahwa bahwa IKAPI (Perikatan Perilis Indonesia) menyatakan $93,4 \%$ orang Indonesia melek huruf artinya masyarakat Indonesia sudah bisa membaca huruf namun perlu meningkatkan kemampuan literasi dan menumbuhkan keinginan membaca. Membaca secara tradisional disebutkan sebagai suatu proses membunyikan simbol bahasa tertulis. Dalam pengertian ini,membaca biasanya disebut sebagai membaca dengan nyaring atau membaca awalan (Ledger \& Margaret, 2018). Membaca juga dapat disebutkan sebagai proses untuk menemukan sebuah informasi yang dikandung dalam isi bacaan untuk mendapatkan pengertian atas bacaan tersebut.

Permasalahan yang pertama dan darurat adalah belajar membaca di sekolah waktu ini adalah bahwa pembelajaran membaca masih dilaksanakan dengan tidak benar atau dengan cara asal asalan. Kebiasaan tidak baik terlihat dari nyatanya bahwa belajar membaca sangat jarang dilaksanakan untuk menolong siswa agar mendapatkani kecepatan dan gaya baca yang tepat melainkan hanya ditujukan untuk kepentingan praktis belaka yakni siswa mampu menjawab pertanyaan bacaan (Tarigan, 2010 : 143).

Rendahnya keinginan baca disebabkan oleh beberapa hal diantaranya tidak sahabatnya harga buku dan minimnya fasilitas perpustakaan yang menyebabkan membaca tidak lagi sebagai sarana pembelajaran dan hiburan bagi masyarakat Indonesia.zaman ini ini masyarakat Indonesia lebih memilih mnonton dan melihat televisi dibanding membeli buku.

Di SDN Pancawati setelah dilakukan penelitian dan observasi didapatkan hasil bahwa di SDN Itu terdapat banyak buku bacaan pahlawan tapi fasilitas perpustakaan yang kurang memadai dan setelah terlihat dari hasil pembelajaran banyak siswa yang memiliki nilai dibawah KKM pada pembelajaran IPS pada materi pahlawan. Untuk pemecahan solusi permasalahan ini yaitu dengan cara memperbaiki fasilitas dan menambah fasilitas perpustakaan agar hasil pembelajaran siswa menjadi meningkat dan lebih baik dan mencapai KKM. Dari hasil wawancara bersama murid didapatkan hasil pertanyaan jika anak suka membaca buku bergenre kepahlawanan tapi fasilitas perpus 
yang tak ada membuat murid kebingungan mendapatkan tempat membaca yang nyaman. Keinginan membaca perlulah dinaikan agar kemampuan membaca murid indonesia yang menurut pengkajian ada di tingkat 60 dari enam puluh satu negara.

Keinginan bisa dijadikan menyebabkan sesuatu kegiatan dan menjadi hasil dari keikutsertaan dalam suatu kegiatan. sebab itu minat adalah keinginan dari hati untuk belajar ingin mendapatkan informasi, keilmuan, kecakapan melalui usaha, pengajaran atau sesuatu yang pernah terjadi di kehidupan peneliti mencoba menumbuhkan dan mengukur minat membaca cerita pahlawan dan pengaruhnya pada hasil belajar pada mata pelajaran IPS (Sejarah Pahlawan).

Melalui membaca cerita pahlawan diharapkan hasil belajar siswa pada mata pelajaran IPS sejarah pahlawan akan bertambah, hasil pembelajaran diperlukan untuk mengukur sejauh mana pemahaman murid atau peserta didik pada suatu mata pelajaran. Salah satu cara yang dirasa bisa digunakan untuk mengatasi permasalahan tersebut adalah mengembangkan minat membaca cerita pahlawan dan pemenuhan fasilitas perpustakaan didasarkan latar belakang peneliti senang untuk mengadakan penelitian dengan tujuan untuk merevisi dan meningkatkan minat membaca peserta didik di kelas $\mathrm{V}$ (Lima) dengan judul : "Pengaruh Minat Membaca Cerita Pahlawan (Nasional) terhadap Hasil Belajar di Kelas V (LIMA) SDN Pancawati 02, pada Mata Pelajaran IPS.

\section{MATERI DAN METODE}

\section{Sampel Penelitian}

Jumlah dari bagan atau memiliki karakteristik dari populasi (Sugiyono,
2015). Dengan kata lain adalah sebagian anggota populasi yang dijadikan di penelitian. Pada penelitian ini menggunakan sampel jenuh yakni sampel apanila semua anggota populasi digunakan sampel, apabila volume populais relatif sedikit atau kurang dari 30 orang. Jumlah sampel penelitian dapat dilihat pada Tabel 1.

Tabel 1 Jumlah sampel penelitian

\begin{tabular}{clr}
\hline No & Kelas & Jumlah peserta didik \\
\hline 1 & VA & 30 \\
2 & VB & 30 \\
Jumlah & 60 \\
\hline
\end{tabular}

\section{Variabel pengkajian}

Dua variabel yang yang dijadikan dalam penelitian ini yaitu variabel bebas dan terikat. Independent variable (Variabel bebas) dan dependent variabel (Variabel terikat) variabel $\mathrm{x}=$ Minat membaca variabel $\mathrm{y}=$ Hasil pembelajaran.

\section{Definisi Operasional Variabel}

\section{Pengertian Minat Membaca}

Keinginan baca ialah kemauan yang levelnya naik dijalani berusahanya seseorang untuk membaca. Orang yang mempunyai keinginan membaca yang kuat akan diwujudkan dalam kesediaannya untuk mendapat bahan bacaan dan kemudian membacanya atas kesadaran sendiri.

\section{Hasil Belajar}

Hasil pembelajaran adalah kebisaan yang diperoleh anak setelah melalui kegiatan belajar Berdasarkan penjabaran di atas dapat ditarik hasil akhir bahwa hasil pembelajaran adalah penilaian pada hasil belajar siswa untuk mengetahui sejauh mana ia telah mencapai target belajar. Hasil belajar adalah perubahan model model 
perilaku, nilai-nilai, sikap, apresiasi dan keterampilan siswa

\section{Tempat dan Waktu Penelitian}

Penelitian ini akan dilaksanakan di Sekolah Dasar Negeri Pancawati 02 yang beralamat di Kampung Lemah Neundeut Kecamatan Caringin Kabupaten Bogor. Waktu penelitian dilaksanakan selama Bulan Maret 2017 sampai bulan Mei 2017 Dalam kurun waktu tersebut peneliti membagi penelitian ini ke dalam beberapa tahapan. Yaitu tahap persiapan, tahap pengumpulan data, tahap pengolahan dan analisis data, serta tahap penulisan laporan.yang kesatu tahap persiapan penelitian yaiu mempersiapkan apa saja yang harus dibawa untuk mengkaji yang kedua tahap pengumpulan data yaitu dengan menyebar angket mewawancara subyek yang akan diteliti lalu dokumentasi dll, yang ketiga tahap pengolahan data setelah didapatkan data baru diolah dan dianalisis data itu lalu dibuat laporannya.

\section{Teknik Pengumpulan Data}

Dalam penelitian ini teknik pengumpulan data yang digunakan peneliti antara lain: Skala likert, observasi, wawancara dan dokumentasi. Untuk mengetahui minat membaca cerita pahlawan dan hasil pembelajaran murid peneliti menggunakan skala likert sedangkan teknik observasi wawancara dan dokumentasi digunakan untuk melengkapi data. Wawancara dilakukan kepada guru dan siswa, dokumentasi berupa poto rekaman dan lainlain.

Sebelum digunakan pada responden penelitian, instrumen penelitian di uji coba terlebih dahulu dengan uji validitas dan uji reabilitas, uji validitas digunakan untuk mengetahui sejauh mana suatu alat ukur mampu mengukur apa yang akan diukur (Syofian Siregar,2013: 75) sedangkan reabilitas instrumen berkaitan dengan masalah adanya kepercayaan Pada alat instrumen, ketepatan instrumen serta keajegan atau konsistensi hasil pengukuran (H Bisri dan M Ichsan, 2015: 88). Adapun uji validitas yang digunakan yaitu teknik korelasi product moment menggunakan bantuan SPSS 21.0.

\section{Observasi}

Pengamatan secara langsung Pada objekobjek yang dijadikan sumber permasalahan, pengamatan sekolah apa yang terjadi selama pembelajaran pengamatan sikap siswa, dan tergantung pada yang akan peneliti kaji. Misal peneliti akan mengkaji masalah keinginan membaca bisa diobservasi bagaimana keadaan perpus atau bahan membacanya.

\section{Kuesioner angket}

Kuesioner angket sdalah alat pengumpul data adalah sejumlah pertanyaang yang tertulis yang harus dijawab oleh responden.

\section{Dokumentasi}

Menggunakan metode ini karena variabel dependent yaitu hasil pembelajaran murid dapat dikumpulkan dan di identifikasi.

\section{Wawancara}

Wawancara digunakan supaya kita tahu kelebihan dan kekurangan guru sebagai evaluasi pada pembelajaran selanjutnya.

\section{Analisis Deskriptif}

Teknik analisis data yang dipakai dalam pengkajian ini yaitu statistik deskriptif, statistik deskriptif adalah statistik yang digunakan untuk menganalisis data dengan cara mendeskirpsikan atau menggambarkan data yang telah terkumpul sebagaimana adanya tanpa bermaksud membuat kesimpulan yang berlaku untuk umum atau 
generalisasi Dalam pengkajian ini analisis deskriptif dibutuhkan untuk menggambarkan data Minat Membaca dan Hasil Belajar, Analisis deskriptif menggunakan tabel distribusi frekuensi yaitu data yang disusun dalam bentuk kelompok baris berdasarkan kelas-kelas interval dan menurut kategori tertentu.

\section{Analisis Inferensial}

Teknik analisis data yang digunakan dalam penelitian ini yaitu statistikinferensial, Statistik parametris dipakai untuk mengetes bagaimana baiknya objek melalui statistik atau mengetahui berapa ukuran populasi melalui data sampel. Sebelum dilakukan analisis regresi untuk mengetahui Pengaruh Variabel $X$ Minat Membaca Cerita kepahlawanan Pada Variabel Y Hasil Belajar, harus diketahui terlebih dahulu apa maksud berhubung atau kolerasi antar variabel yang diteliti. Analisis korelasi merupakan suatu bentuk analisis inferensial yang digunakan untuk melihat hubungan antara variabel-variabel peneltian (Supardi, 2012:157).

\section{Instrumen Penelitian}

Instrumen penelitian yang digunakan dalam penelitian ini yaitu menggunakan kuisioner terbuka, (Angket) responden diminta untuk mengisi setiap kolom pertanyaan dengan memberikan tanda ceklis $(\sqrt{ })$ pada alternative jawaban yang telah disediakan.

\section{Perhitungan Skor}

Dalam pengkajian ini, peneliti menggunakan kuisioner terbuka yaitu responden diberi kebebasan untuk menjawab setiap pertanyaan. Kuisioner tersebut menggunakan skala likert. Skala likert digunakan untuk mengukur sikap, pendapat dan persepsi seseorang maupun persepsi kelompok mengenai fenomena sosial tertentu. Dengan skala likert maka subjek yang akan diukur telah dijabarkan menjadi indikator variabel. Kemudian indikator tersebut dijadikan sebagai acuan untuk menyusun instrument yang berupa pertanyaan atau pernyataan (Sugiyono, 2015:93) Setiap jawaban dihubungkan dengan bentuk pernyataan atau sikap yang diungkapkan dengan kata-kata sebagai seperti pada Tabel 2 .

Tabel 2 Skor Skala Likert

\begin{tabular}{llrr}
\hline \multirow{2}{*}{ No. } & \multicolumn{1}{|}{ Item } & \multicolumn{2}{c}{ Skor Jawaban } \\
\cline { 3 - 4 } & Positif & Negatif \\
\hline 1. & Sangat Setuju & 5 & 1 \\
2. & Setuju & 4 & 2 \\
3. & Ragu-Ragu & 3 & 3 \\
4. & Tidak setuju & 3 & 3 \\
5. & Sangat tidak setuju & 1 & 1 \\
\hline
\end{tabular}

\section{HASIL DAN PEMBAHASAN}

\section{Hasil}

\section{Pengujian Validitas dan Pentesan Realibilitas Hasil Belajar}

\section{Uji Validitas}

Validitas adalah suatu ukuran yang menunjukan level-level kevalidan atau kesahihan sesuatu instrumen uji validitas yang digunakan yaitu teknik korelasi product moment dengan rumus sebagai berikut.

$$
r_{x y}=\frac{n \cdot \sum x y-\sum x \sum y}{\sqrt{\left[n \sum x^{2}-\left(\sum x\right)^{2}\right]\left[n \sum y^{2}\left(\sum y\right)^{2}\right]}}
$$

Keterangan : ${ }^{r_{x y}}=$ koefesien korelasi antara variabel $\mathrm{X}$ dan $\mathrm{Y} ; \mathrm{N}=$ banyaknya peserta tes; $\mathrm{X}=$ variabel bebas; $\mathrm{Y}=$ variabel terikat.

Untuk instrumen berupa angket, digunakan validitas konstruk (Contruk Validity), dalam uji validasi ini dapat dipakaikan pendapat dari ahli Judgment Experts). Di dalam hal ini sesudah instrumen 
dirangkai mengenai hal-hal yang akan diukur dengan berlandaskan penjelasan maka langkah selanjutnya dikonsultasikan dengan ahli. Uji validitas yang dipakai yaitu teknik korelasi product moment.

Sebelum digunakan pada responden penelitian yang sebenarnya, instrumen penelitian diuji coba terlebih dahulu.sebelum kuisoner disebar kepada responden peneliti mencek kepada seseorang yang mampu atau punya keahlian validasi, setelah pengecekan sudah dilakukan barulah kuesioner atau angket bisa disebar Tujuan dan uji coba adalah untuk menyeleksi item-item manakah yang valid dan reliabel agar dapat digunakan dalam penelitian. Uji coba dilaksanakan pada tanggal 20 Maret 2017 dengan menggunakan sampel sebanyak 30 murid kelas V SDN Pancawati.

Data yang telah diperoleh kemudian dianalisis untuk mengetahui kualitas dari instrumen tersebut. Untuk perhitungan analisis skala keinginan membaca cerita pahlawan digunakan bantuan komputer dengan program Microsoft Excel dan SPSS 21.0 menggunakan rumus korelasi product moment dari Pearson. Hasil korelasi antar skor-skor item dengan skor total, diperoleh nilai korelasi pada skala minat membaca cerita pahlawan. Berdasarkan tabel 3 dapat diketahui bahwa instrumen Minat membaca cerita pahlawan dengan jumlah item 30, setelah dianalisis dengan rumus korelasi product moment diperoleh sebanyak 17 item pakai, 6 item revisi, dan 6 item buang.

Tabel 3 Hasil uji validitas minat membaca cerita pahlawan

\begin{aligned} & \hline No. Item. Keterangan \\ & \hline $2,3,5,6,7,10,12,13,15,16,17,2$ Pakai \\ & $0,21,23,27,28 \\ & 1,4,9,11,14,19$ Revisi \\ & $18,22,24,25,26,29$ Buang \\ & \hline\end{aligned}

\section{Uji Reliabilitas}

Reabilitas menunjuk pada satu pengertian bahwa sesuatu instrumen cukup dapat percaya untuk digunakan sebagai alat pengumpul data karena instrumen tersebut sudah baik. Cara yang digunakan untuk menguji reliabilitas untuk keseluruhan item adalah dengan mengoreksi angka korelasi yang diperoleh dengan memasukannya ke dalam rumus

$$
r_{\text {tot }}=\frac{2 \cdot r_{t t}}{(1+r t t)}
$$

Keterangan: $r_{\text {tot }}=$ angka reliabilitas keseluruhan item; $r_{\mathrm{tt}}=$ angka korelasi belahan pertama dan belahan kedua.

Selanjutnya reliabilitas pada keinginan membaca cerita pahlawan dihitung menggunakan rumus Alpha Cronbach. Dalam perhitungannya menggunakan bantuan SPSS 21.0 seperti pada Tabel 4 .

Tabel 4 Hasil uji reabilitas minat membaca cerita pahlawan

\begin{tabular}{rrr}
$\begin{array}{c}\text { Cronbach's } \\
\text { Alpha }\end{array}$ & $\begin{array}{c}\text { Cronbach's } \\
\text { Alpha Based on } \\
\text { Standardized } \\
\text { Items }\end{array}$ & N of Items \\
\hline .922 & .925 & 30 \\
\hline
\end{tabular}

Dari tabel 4 menunjukan bahwa reabilitas dengan 30 responden dan 30 item diperoleh Alpha Cronbach's 0,925. Hal ini menunjukkan bahwa instrumen tersebut memiliki reliabilitas yang sangat baik.

\section{Deskripsi data}

\section{Minat membaca cerita pahlawan}

Minat membaca cerita pahlawan diukur menggunakan Skala likert yang terdiri dari 25 item pertanyaan yang telah diuji validitas dan reabilitasnya. Berdasarkan hasil data penelitian, diperoleh data seperti pada Tabel 5. 
Tabel 5 Statistik minat membaca cerita pahlawan

\begin{tabular}{lccccr}
\hline \multicolumn{7}{c}{ Descriptive Statistics } \\
\hline minat_membaca & $\mathrm{N}$ & Minimum & Maximum & Mean & Std. Deviation \\
Valid N (listwise) & 30 & 60.00 & 110.00 & 78.8000 & 12.89854 \\
\hline
\end{tabular}

Berdasarkan tabel 5, didapatkan skor minat membaca cerita pahlawan, skor terendah 60, dan skor tertinggi 110, dengan skor rata-rata 78,80 .

Selanjutnya skor yang diperoleh dibuat menjadi data distribusi frekuensi, untuk memudahkan dalam penyajian data dan supaya lebih sederhana. Tabel 6 merupakan tabel distribusi frekuensi.

Tabel 6 Distribusi frekuensi minat membaca cerita pahlawan

\begin{tabular}{clrr}
\hline No & Interval & Frekuensi & Presentase \\
\hline 1 & $60-65$ & 2 & $6,7 \%$ \\
2 & $66-71$ & 8 & $33,3 \%$ \\
3 & $72-77$ & 6 & $16,7 \%$ \\
4 & $78-83$ & 4 & 13,3 \\
5 & $84-89$ & 3 & $6,7 \%$ \\
6 & $90-95$ & 3 & $10 \%$ \\
7 & $96-101$ & 3 & $10 \%$ \\
8 & $102-109$ & - & 0 \\
9 & $110-115$ & 1 & $3,3 \%$ \\
Jumlah & 30 & $100 \%$ \\
\hline
\end{tabular}

\section{Hasil pembelajar Atau Hasil Belajar dalam pandangan Islam}

Pandangan al-Qur'an kepada aktivitas pembelajaran, antara lain dapat dilihat dalam kandungan ayat 31-33 al-Baqarah:

$$
\text { و و علم عادم الأسماء كلها ثم عرضهم على الملائكة فقال أنبئوني }
$$

Artinya: Dan Dia memberi pengajaran kepada nabi adam bernama-nama (bendabenda) seluruhnya, kemudian mengemukakannya kepada para Malaikat lalu berfirman: "Sebutkanlah kepada-Ku nama berbagai benda itu ini bila kamu adalah orang-orang yang benar!".

Ayat di atas memiliki arti bahwa jauh sebelum kita, nabi Adam sudah diperintahkan belajar ayat ini juga menginformasikan bahwa manusia diberi kelebihan oleh ALLAH potensi untuk mengetahui apa arti nama maksudnya apa atau fungsi dan karakter penjelasan berbagai macam bentuk benda, contohnya kegunaan api, angin dan sebagainya. Dan ia juga dianugrahi untuk berbicara dan punya komunikasi yang baik dan. Itulah kenapa maka pengajaran bagi seorang anak atau peserta didik bukanlah dimulai melalui pengajaran "kata bekerja", tetapi awalannya dahulu mengetahui berbagai macam nama. Ini ayah, Ibu, anak, pena, buku dan lain sebagainya.

Hasil Belajar di ukur menggunakan skala likert yang terdiri dari 30 item pertanyaan yang telah di uji validitas dan reabilitasnya. Berdasarkan hasil data penelitian, diperoleh data sebagai berikut: Selanjutnya skor yang didapat, dibuat menjadi data distribusi frekuensi, untuk memudahkan dalam penyajian data dan supaya lebih sederhana. Distribusi frekuensi terdapat pada Tabel 7. 
Tabel 7 Statistik deskripsi hasil belajar

\begin{tabular}{lccccr}
\hline \multicolumn{5}{c}{ Descriptive Statistics } \\
\hline Hasil_belajar & N & Minimum & Maximum & Mean & Std. Deviation \\
\hline Valid N (listwise) & 30 & 55.00 & 90.00 & 70.4333 & 9.89839 \\
\hline
\end{tabular}

Berdasarkan tabel 7, didapatkan skor minat membaca cerita pahlawan, skor terendah 55, dan skor tertinggi 90, dengan skor rata-rata 70,43 . Selanjutnya skor yang didapat, dibuat menjadi data distribusi frekuensi, untuk memudahkan dalam penyajian data dan supaya lebih sederhana. Distribusi frekuensi tersebut dapat dilihat pada Tabel 8.

Tabel 8 Distribusi frekuensi hasil belajar

\begin{tabular}{llrr}
\hline No & Interval & Frekuensi & Presentase \\
\hline 1 & $55-60$ & 6 & $20 \%$ \\
2 & $61-66$ & 6 & $20 \%$ \\
3 & $67-72$ & 5 & $16,6 \%$ \\
4 & $73-78$ & 2 & $66,6 \%$ \\
5 & $79-84$ & 8 & 26,6 \\
6 & $85-90$ & 3 & $30 \%$ \\
Jumlah & & 30 & $100 \%$ \\
\hline
\end{tabular}

Tabel 9 Hasil uji normalitas

\begin{tabular}{|c|c|c|c|}
\hline & & Minat membaca & Hasil belajar \\
\hline $\mathrm{N}$ & & 30 & 30 \\
\hline \multirow[t]{2}{*}{ Normal Parameters ${ }^{\mathrm{a}}$} & Mean & 78.80 & 70.43 \\
\hline & Std. Deviation & 12.899 & 9.898 \\
\hline \multirow[t]{3}{*}{ Most Extreme Differences } & Absolute & .216 & .142 \\
\hline & Positive & .216 & .142 \\
\hline & Negative & -.113 & -.140 \\
\hline Kolmogorov-Smirnov Z & & 1.182 & .777 \\
\hline Asymp. Sig. (2-tailed) & & .122 & .583 \\
\hline \multicolumn{4}{|l|}{ a. Test distribution is Normal } \\
\hline
\end{tabular}

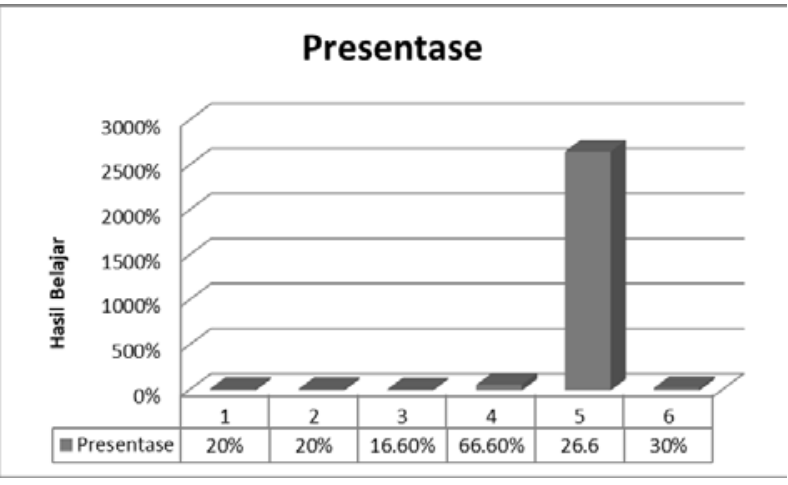

Gambar 1 Diagram batang variabel hasil belajar.

\section{Uji Prasyarat Analisis Data}

\section{Uji Normalitas}

Penelitian uji normalitas ini menggunakan uji Kolmogorov-Smirnov, karena data yang di gunakan merupakan data kelompok. Berikut adalah hasil uji signifikansi dengan menggunakan bantuan program SPPS 21.0 di bawah adalah contoh pengkajiannya. belajar 0,583 > dari signifikansi 0,05. Maka 
Tabel 10 Hasil perhitungan uji linearitas

\begin{tabular}{|c|c|c|c|c|c|c|c|}
\hline \multicolumn{8}{|c|}{ ANOVA Table } \\
\hline & & & $\begin{array}{l}\text { Sum of } \\
\text { Squares }\end{array}$ & Df & $\begin{array}{l}\text { Mean } \\
\text { Square }\end{array}$ & $\mathrm{F}$ & Sig. \\
\hline \multirow{5}{*}{$\begin{array}{l}\text { hasil_belajar * } \\
\text { minat_membaca }\end{array}$} & Between & (Combined) & 2170.367 & 17 & 127.669 & 2.283 & .075 \\
\hline & a Groups & Linearity & 1782.487 & 1 & 1782.487 & 31.878 & .000 \\
\hline & & $\begin{array}{l}\text { Deviation from } \\
\text { Linearity }\end{array}$ & 387.880 & 16 & 24.242 & .434 & .940 \\
\hline & Within Gr & & 671.000 & 12 & 55.917 & & \\
\hline & Total & & 2841.367 & 29 & & & \\
\hline
\end{tabular}

Dalam uji ini ditentukan bahwa signifikansi $(\alpha)$ sebesar $5 \%$ berdasarkan kotak yang tertera di atas dapat kita ketahui bahwa sig liniearity $(0,000)<$ nilai $\alpha(0,05)$, dan sig deviation from linearity $(0,940)>\alpha$ $(0,05)$. Berdasarkan dua pernyataan tersebut dapat ditarik garis akhir bahwa variabel Minat membaca cerita pahlawan dan hasil belajar siswa mempunyai hubungan yang linear dan signifikan.

\section{Pengujian Hipotesis Statistika}

\section{Mencari Korelasi Antar Variabel}

Untuk mengetahui ada atau tidaknya tentang berhubungan antara Minat membaca cerita pahlawan dengan Hasil Belajar, dilakukan analisis pendataan korelasi product moment dari Pearson. Berikut adalah tabel kolerasi Product Moment dengan memakai dan dengan bantuan aplikasi SPSS 21.0. contoh pengkajiannya terdapat pada Tabel 11.

Tabel 11 Kolerasi product moment

\begin{tabular}{llrr}
\hline \multicolumn{2}{c}{ Correlations } & \\
\hline \multirow{2}{*}{ Minat_membaca } & Minat_membaca & Hasil_Belajar \\
& Pearson Correlation & 1 & $.792^{* *}$ \\
& Sig. (2-tailed) & & .000 \\
Hasil_Belajar & $\mathrm{N}$ & 30 & 30 \\
& Pearson Correlation & $.792^{* *}$ & 1 \\
& Sig. (2-tailed) & .000 & 30 \\
\hline
\end{tabular}

**. Correlation is significant at the 0.01 level (2-tailed).

Dari tabel 11 tersebut diketahui bahwa nilai korelasii ${ }^{r}{ }_{x y}=0.792$, selanjutnya nilai korelasi $\mathrm{r}_{\mathrm{xy}}$ dibandingkan dengan nilai $\mathrm{r}$ product moment untuk $\mathrm{N}=28$ dan taraf signifikansi $5 \%$ yaitu $r=0,374$. Dengan demikian $r$ hitung $>r_{\text {tabel }}(0,792>0,374)$, maka $\mathrm{H}_{0}$ ditolak dan disimpulkan terdapat korelasi yang signifikan berkesinambungan antara minat membaca cerita pahlawan dengan hasil belajar.

\section{Persamaan Regresi}

Analisis persamaan regresi dilakukan untuk mengetahui bagaimana pengaruh minat membaca cerita pahlawan Pada hasil belajar murid, contohnya terdapat pada tabel 12 . 
Tabel 12 Persamaan regresi

\begin{tabular}{|c|c|c|c|c|c|c|}
\hline \multicolumn{7}{|c|}{ Coefficients $^{\mathrm{a}}$} \\
\hline \multirow[b]{2}{*}{ Model } & & \multicolumn{2}{|c|}{ Unstandardized Coefficients } & \multirow{2}{*}{$\begin{array}{c}\begin{array}{c}\text { Standardized } \\
\text { Coefficients }\end{array} \\
\text { Beta } \\
\end{array}$} & \multirow[b]{2}{*}{$\mathrm{T}$} & \multirow[b]{2}{*}{ Sig. } \\
\hline & & $\mathrm{B}$ & Std. Error & & & \\
\hline \multirow[t]{2}{*}{1} & (Constant) & 22.537 & 7.066 & & 3.189 & .003 \\
\hline & Minat_membaca & .608 & .089 & .792 & 6.865 & .000 \\
\hline
\end{tabular}

a. Dependent Variable: Hasil_Belajar

Berdasarkan tabel 12 diperoleh nilai koefisien (b) bertanda positif 0.608, dapat dikatakan dan ditarik garis akhir hubungan antara minat membaca cerita pahlawan dengan hasil belajar merupakan hubungan yang berbanding lurus, artinya semakin tinggi Minat membaca cerita pahlawan maka semakin naik pula hasil belajarn siswa. Adapun jumlah dalam setiap tingkatan yaitu $\widehat{\boldsymbol{Y}}_{0,608 .+0,776 \mathrm{X}}$
Adapun persamaan regresi yang diperoleh dan diambil dalam penelitian ini yaitu 22.537. Inilah pengkajian penilai persamaan regresi.

\section{Signifikansi persamaan regresi}

\section{Uji F}

Perhitungan signifikansi persamaan dengan bantuan hitungan dari SPPS 21.0 terdapat pada Tabel 13.

Tabel 13 Uji F

\begin{tabular}{llrrrrr}
\hline & Model & Sum of Squares & \multicolumn{1}{c}{ Df } & Mean Square & F & \multicolumn{1}{c}{ Sig. } \\
\hline 1 & Regression & 1782.487 & 1 & 1782.487 & 47.134 & $.000^{\mathrm{a}}$ \\
& Residual & 1058.880 & 28 & 37.817 & & \\
Total & 2841.367 & 29 & & & \\
\hline
\end{tabular}

Berdasarkan hasil penghitungan SPSS Uji Signifikansi (Uji F) diatas dapat terlihat nilai $F$ hitung $>$ Dari $F_{\text {tabel }}$ yaitu $47.134>4,061$ dengan tingjkat signifikansinya $<0,05$ yaitu 0,000 Sehingga dapat disimpulkan bahwa minat membaca cerita pahlawan (Variabel Tabel 14 Uji T
$\mathrm{X}$ ) berpengaruh Pada hasil belajar siswa (Variabel Y)

\section{Uji T}

Penghitungan Uji $\mathrm{T}$ dengan menggunakan bantuan SPSS 21.0 terdapat pada Tabel 14.

\begin{tabular}{|c|c|c|c|c|c|c|}
\hline \multicolumn{7}{|c|}{ Coefficients $^{a}$} \\
\hline \multirow[b]{2}{*}{ Model } & & \multicolumn{2}{|c|}{ Unstandardized Coefficients } & $\begin{array}{c}\text { Standardized } \\
\text { Coefficients }\end{array}$ & \multirow[b]{2}{*}{$\mathrm{T}$} & \multirow[b]{2}{*}{ Sig. } \\
\hline & & $\mathrm{B}$ & Std. Error & Beta & & \\
\hline \multirow[t]{2}{*}{1} & (Constant) & 22.537 & 7.066 & & 3.189 & .003 \\
\hline & Minat_membaca & .608 & .089 & .792 & 6.865 & .000 \\
\hline
\end{tabular}

a. Dependent Variable: Hasil_Belajar

Berdasarkan hasil penghitungan SPSS Uji Signifikansi (Uji T) diatas dapat terlihat nilai $\mathrm{F}$ hitung $>$ Dari $F_{\text {tabel }}$ yaitu 6,865 $>4,061$ dengan tingkat signifikansinya $<0,05$ yaitu
0,000 Sehingga dapat disimpulkan bahwa minat membaca cerita pahlawan (Variabel $\mathrm{X}$ ) berpengaruh Pada hasil belajar siswa (Variabel Y). 


\section{Koefisien Determinasi}

Berdasarkan Tabel 15 didapatkan korelasi antara Minat membaca cerita pahlawan dan Hasil Belajar adalah 0,792 artinya terdapat hubungan yang positif dan signifikan sebesar 0,792 antara minat membaca cerita pahlawan dengan hasil belajar. Koefisien determinasi yaitu $0,792^{2}=0,627$. Dan nilai hasil belajar terbesar siswa sebesar $62,7 \%$ sedangkan 37,3 Hasil belajar siswa dipengaruhi oleh faktor lain.

Tabel 15 Koefisien determinasi

Model Summary

\begin{tabular}{|c|c|c|c|c|}
\hline Model & $\mathrm{R}$ & $\begin{array}{c}\mathrm{R} \\
\text { Square }\end{array}$ & $\begin{array}{l}\text { Adjusted } \\
\text { R Square }\end{array}$ & $\begin{array}{l}\text { Std. Error } \\
\text { of the } \\
\text { Estimate }\end{array}$ \\
\hline 1 & $.792^{\mathrm{a}}$ & .627 & .614 & 6.14956 \\
\hline
\end{tabular}

\section{Hipotesis Statistika}

Hipotesis dalam statistik merupakan pernyataan penghitungan statistik tentang parameter dan jumlah populasi, sedangkan praduga sementara atau hipotesis dalam penelitian merupakan jawaban sementara terhadap rumusan masalah dalam penelitian.

\section{Hipotesis Penelitian}

$\mathrm{H}_{0}$ : Tidak ada pengaruh antara Minat membaca cerita pahlawan Pada Hasil Belajar Siswa Pada mata pelajaran IPS di Kelas V Sekolah Dasar Negeri Pancawati 02.

$\mathrm{H}_{\mathrm{a}}$ : terjadi pengaruh antara Minat membaca cerita pahlawan Pada Hasil Belajar Siswa Pada mata pelajaran IPS di Kelas V Sekolah Dasar Negeri Pancawati 02.

\section{Pembahasan}

Hasil penelitian yang telah didapat dari data yang telah diolah dan di analisis mengenai minat membaca cerita pahlawan dan hasil belajar pada mata pelajaran IPS di SDN Pancawati 02 terjadi beberapa pengaruh yang signifikan antara minat membaca cerita pahlawan dengan hasil belajar IPS di SDN Pancawati 02 Kecamatan Caringin. Dengan melakukan uji hipotesis. Hasil pengujian melalui analisis regresi menunjukkan adanya persamaan regresi $\mathrm{Y}$ 22.537. dapat dikatakan hubungan antara minat membaca cerita para pejuang kepahlawanan dengan hasil belajar merupakan hubungan yang berbanding lurus, artinya semakin naik dan semakin baik Minat membaca cerita pahlawan maka semakin tinggi pula hasil belajar siswa.Adapun jumlah dalam setiap level per level yaitu $\widehat{\boldsymbol{Y}} 0,608++0,776 \mathrm{X}$

Berdasarkan Uji Kolmogrov Smirnov diperoleh signifikansi untuk minat membaca 0,122 dan hasil belajar 0.583 Membaca 0,122 > dari signifikansi 0,05. Maka disimpulkan $\mathrm{H}_{0 . \text { ditolak dan data }}$ berdistribusi normal.

Analisis peneliti juga berpendapat jika anak anak di sdn pancawati gemar membaca cerita pahlawan terlihat dari hasil angket dan ha sil regresi yang tinggi namun karena kurangnya pemenuhan fasilitas perpustakaan seharusnya pemerintah atau pihak sekolah bisa mengadakan perpustakaan dan meningkatkan hasil pembelajaran murid yang rendah dalam mata pembelajaran IPS dan murid dapat membaca dengan nyaman.terlihat dari hasil wawancara yang didapat pada murid yang sebenarnya suka membaca cerita menurut mereka karena mereka bisa tahu bagaimana cerita masa di zaman lampau yang di tuangkan dalam buku bacaan. Hasil pembelajaran pun harus terus dinaikan coba bayangkan apabila keinginan membaca peserta didik baik dan menaik dan hasil belajar naik tak mustahil murid dan peserta 
didik Indonesia bisa bertengger di tingkat dunia.

\section{KESIMPULAN DAN IMPLIKASI}

\section{Kesimpulan}

Hasil berdasarkan pengkajian yang berjudul "Pengaruh minat membaca cerita pahlawan Pada hasil belajar IPS kelas V di SDN Pancawati 02" korelasi antara minat membaca cerita pahlawan dengan hasil belajar diperoleh nilai sebesar $r=0,792$, Dari tabel kolerasi diketahui bahwa nilai korelasii ${ }^{r}{ }_{x y}=0.792$, selanjutnya nilai korelasi ${ }^{r}$ xy dibandingkan dengan nilai $r$ product moment untuk $\mathrm{N}=28$ dan taraf signifikansi $5 \%$ yaitu $r=0,374$. Dengan demikian $r$ hitung $>r_{\text {tabel }}(0,792>0,374)$, maka $\mathrm{H}_{0}$ ditolak dan disimpulkan terdapat korelasi yang signifikan antara minat membaca cerita pahlaw an dengan hasil belajar. Artinya terdapat pengaruh antara minat membaca cerita pahlawan dengan hasil belajar di SDN Pancawati 02 Kecamatan Caringin Kabupaten Bogor.

\section{Implikasi}

Pengaruh minat membaca cerita pahlawan pada hasil pengajaran dapat menjadi cambuk atau saran bagi pihak pemerintah untuk memberikan fasilitas perpustakaan yang ada dan baik, untuk menaikan keinginan membaca murid dan bisa mengubah persepsi dunia jika murid Indonesia rendah dalam keinginan membaca sebuah buku. Dan meningkatkan hasil belajar murid dengan memakai cara misalnya model pembelajaran yang menarik dengan berpatokan pada paikem pembelajaran aktif kreatif inovatif dan memberikan penjelasan kepada murid dengan membaca akan membuat hasil belajar menjadi menaik karena di dalam pembelajaran IPS bercerita pahlawan sangat banyak materi membaca dan memberi penggambaran bahwa membaca akan membuka jendela dunia dan dengan hasil pembelajaran tinggi akan membuat siswa indonesia lebih berkembang dan dihargai di mata dunia dan bisa bersaing dengan negara lain. Perlunya perdorongan yang tinggi dari guru untuk menaikan kemauan membaca anak, bisa dengan materi mendongeng, mengadakan satu atau dua jam untuk jam membaca di perpustakaan, karena dalam materi kepahlawanan sangat penuh mengandung cerita.

Analisis peneliti juga berpendapat jika anak anak di sdn pancawati gemar membaca cerita pahlawan terlihat dari hasil angket dan ha sil regresi yang tinggi namun karena kurangnya pemenuhan fasilitas perpustakaan seharusnya pemerintah atau pihak sekolah bisa mengadakan perpustakaan dan meningkatkan hasil pembelajaran murid yang rendah dalam mata pembelajaran IPS dan murid dapat membaca dengan nyaman.terlihat dari hasil wawancara yang didapat pada murid.

\section{DAFTAR PUSTAKA}

Henry, G.T. (2008). Membaca. Bandung : Angkasa Bandung.

Lembaga, Percetakan AL-QUR'AN. (2010) Al-Qur' An Dan Terjemahnya. Ciawi: Lembaga, Percetakan AL-QUR'AN.

Susan, L. \& Margaret, M.K (2018). Reading Aloud: Children's Attitudes toward Being Read to at Home and at School. Australian Journal of Teacher Education, 43(3): 124139. 
